\title{
IMPROVEMENT OF THE BIOCHEMISTRY COURSE FOR PHARMACY STUDENTS AT THE MEDICAL UNIVERSITY OF VARNA

\author{
Milena Pasheva ${ }^{1}$, Milka Nashar ${ }^{1}$, Yoana Kiselova-Kaneva ${ }^{1}$, Diana Ivanova ${ }^{1}$, \\ Bistra Galunska ${ }^{2}$ \\ ${ }^{1}$ Faculty of Pharmacy, Department of Biochemistry, Molecular Medicine and \\ Nutrigenomics, Medical University of Varna, Bulgaria
} \\ ${ }^{2}$ Department of Pharmaceutical Technology, Medical University of Varna, Bulgaria
}

\begin{abstract}
Research results on students' content regarding the basic biochemistry course of the "Pharmacy" programme at Medical University Varna are presented based on a three year survey (from 2011/2012 up to 2013/2014 academic year). The respondents comprised $80 \%$ of all pharmacy students. The questionnaire involved evaluation of course content, appropriateness of available study materials, assessment of students' knowledge during the semester, as well as the final exam. The students evaluated the course content as being up-to-date ( $90 \%$ of the respondents) and a prerequisite for their future specialized training in pharmaceutical sciences $(70 \%)$. Based on the student opinion from the survey a book with specialized study materials (a collection of theoretical and practical tasks and tests) was prepared and published. Furthermore, beginning from the current 2014/2015 academic year all lecture notes were uploaded online using the new Medical University of Varna e-learning platform Blackboard. Continuous assessment approach was adopted in addition to the final exam, as required by most of the students involved in the survey. In conclusion, the biochemistry teaching was optimized and adjusted to the specific requirements of the pharmacy students, thus contributing to a better education quality of the future professionals.
\end{abstract}

Keywords: biochemistry course improvement, questionnaire survey, pharmacy students, pharmacy education

\section{INTRODUCTION}

At the present time the demands made on a university graduate's abilities have changed radically, namely on the level of his readiness for professional practice, on his ability to think creatively, to an-

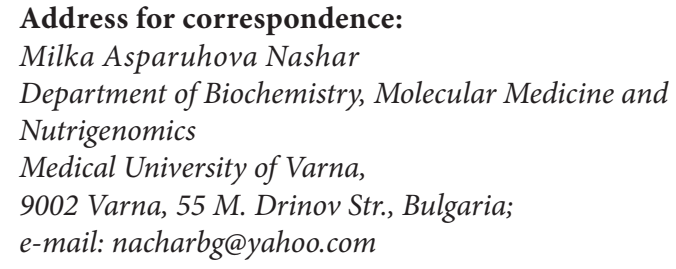

Received: April 27, 2015

Accepted: May 19, 2015 alyze and solve problems. The rapid and exponential development of scientific knowledge requires active learning and producing such teaching tools that could focus the education in biochemistry on the specific knowledge required for future pharmacists. The modernization of the Biochemistry course for pharmacy students aimed to provide students with a more practical and interesting approach to biochemistry and allow them to understand in depth the biochemical processes and the mechanism of drug action.

The dynamic nature and complexity of biochemical processes is one of the reasons biochemistry to be found by the students as one of the highly difficult disciplines. The basic biochemistry course 
is mandatory for 5 -th semester pharmacy students at the Medical University of Varna. The optimization of the course as well as the teaching methods is part of the overall strategy of the Faculty of Pharmacy at the Medical University of Varna. Improving the course content for pharmacy students and introducing new didactic tools of teaching is a part of the socalled active learning philosophy (Lodish et al 2004, Michael et al 2006). Introducing new and contemporary teaching approaches will increase the quality of education, students' awareness and competence. In this regard, proper and timely surveys for feedback among the students are the basis for the introduction of innovative teaching methods oriented to the specific needs of future masters of pharmacy.

\section{OBJECTIVES}

We aimed to evaluate the students' content regarding the basic biochemistry course of the
"Pharmacy" programme at Medical University Varna as well as their satisfaction at the end course.

\section{SUBJECTS AND METHODS}

We surveyed a sample of 94 third-year pharmacy students, comprising $80 \%$ (94/130) of all pharmacy students taught at the Faculty of Pharmacy, Medical University - Varna for a period of three academic years (2011 - 2014). All pharmacy students who successfully passed their final exam in biochemistry were asked to fill out an anonymous questionnaire.

The questionnaire comprised of 18 questions divided into the following groups: evaluation of course content, appropriateness of available study materials, assessment of students' knowledge during the semester, as well as the final exam.

\section{STATISTICAL ANALYSIS}

Responses in the survey were categorized as either correct or incorrect, and blank responses were

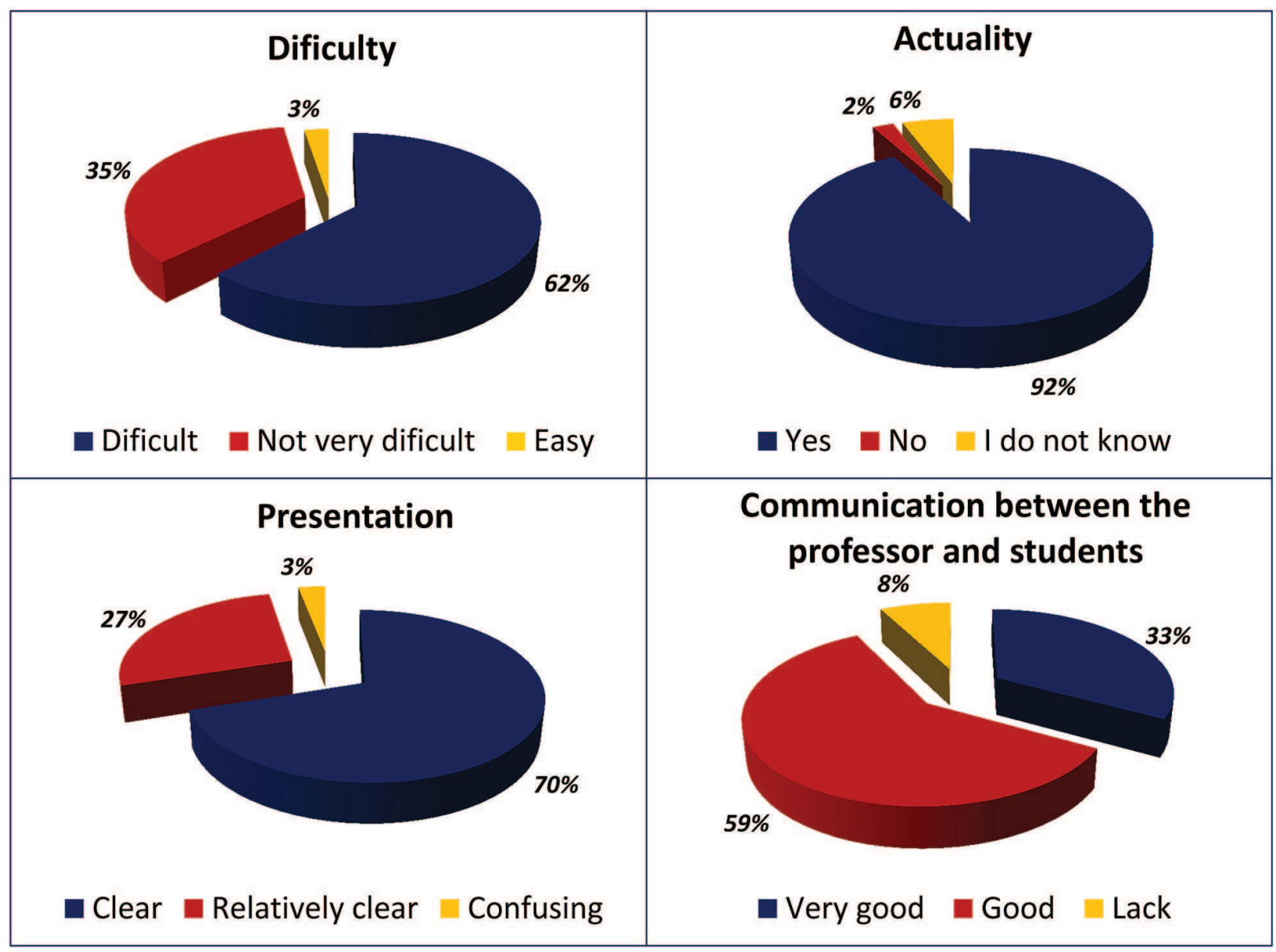

Fig. 1. Assessment of lectures content and presentation 
Milena Pasheva, Milka Nashar, Yoana Kiselova-Kaneva et al.

ignored in the data analysis. Descriptive analysis was used for assessment of the results of the survey.

\section{RESULTS}

When the students were asked whether the lecture content is difficulty or not, $65 \%$ of them evaluated the lectures as difficult, $35 \%$ as not so difficult and 3\% as easy (Fig. 1). Most of the students evaluated the lectures as topical (92\%) and only 6\% did not provide evaluation. Regarding the clarity of lectures, $70 \%$ of the responders answered that the lectures are clear and $27 \%$ - relatively clear. The contact between the lecturer and students during the lecture was estimated as very good (59\%), good (33\%) and no contact (8\%).

Other set of questions was related to the seminar system and the role of the assistant professor for better understanding of the topics.
For the questions related to the amount of teaching material for seminar work, $54 \%$ of the students answered that the study material they had to prepare for seminars is too much, $43 \%$ - corresponding to their knowledge, and 3\% insufficient. Regarding the number of practical exercises - 54\% evaluate them as sufficient, $28 \%$ insufficient and $18 \%$ as unnecessary. Most of the students (83\%) evaluated the explanations of the assistant professor during the seminars as "very clear", $15 \%$ as "clear", and only $2 \%$ as "obscure". The assistant professor's awareness of the students' success was evaluated by "yes/no" questions. Positive answers were given by $91 \%$ of the students and only $9 \%$ answered negatively (Fig. 2).

The use of the lecture course for the students' overall preparation for the final biochemistry exam was evaluated as "very useful" (46.0\%), "useful" (38.3\%) and sufficient (15.7\%). The advantage of the

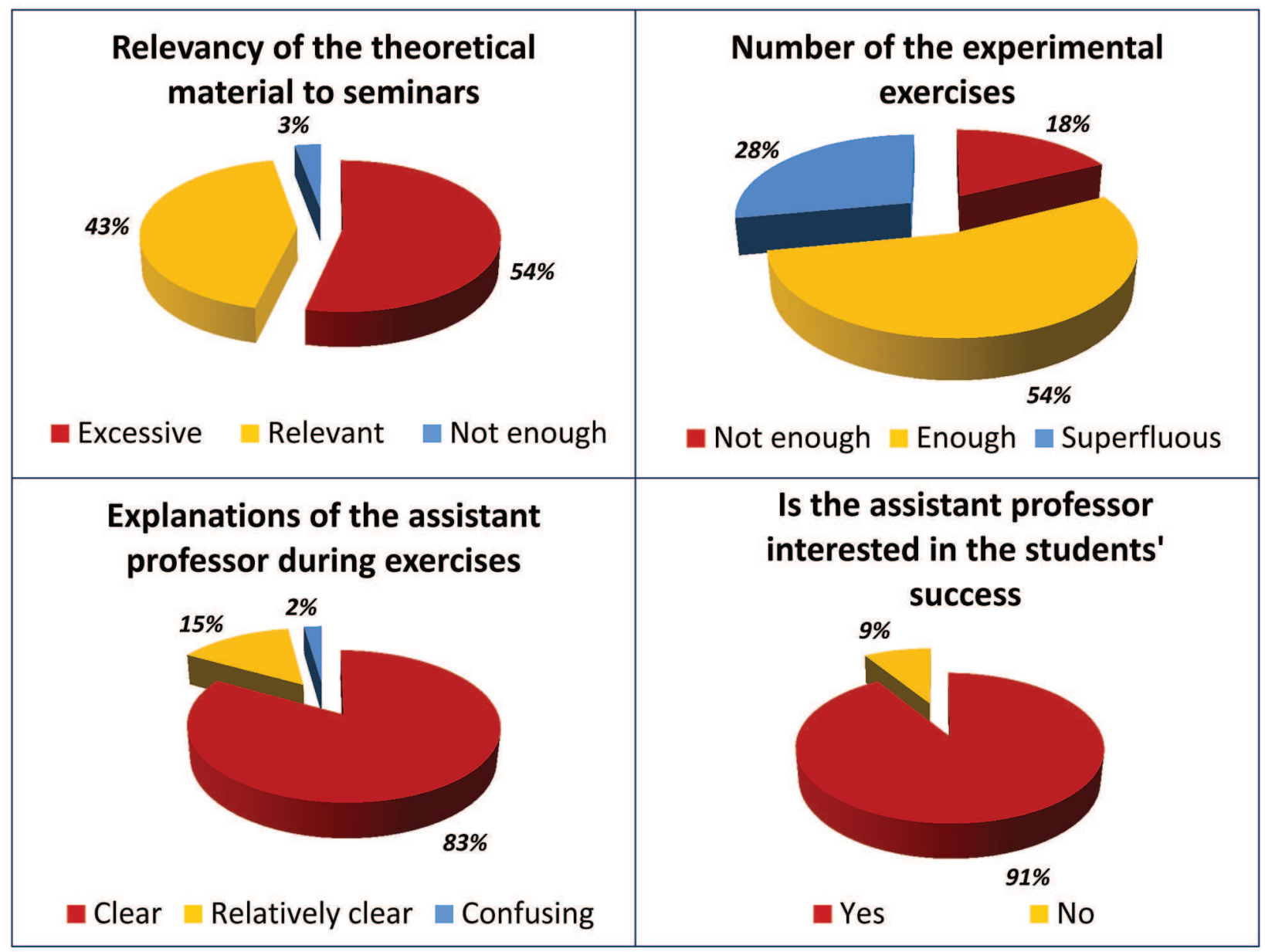

Fig. 2. Assessment of seminars and practicals content and organization 
seminar sessions for the success of the final exam was scored as very good (39.6\%), good (43.2\%), and adequate (17.2\%). Nobody marked "useless" as an answer for lectures and seminars as tools for successful taking the final biochemistry exam (Fig. 3). modern concepts, stresses the most recent advances in the discipline. The students were required to solve the exercises for a given topic before the seminar and to discuss their answers and explanations with the assistant professor during the seminar.
A

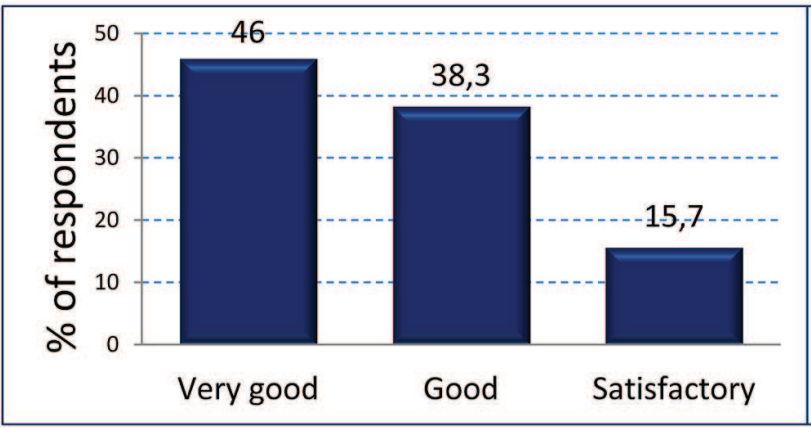

B

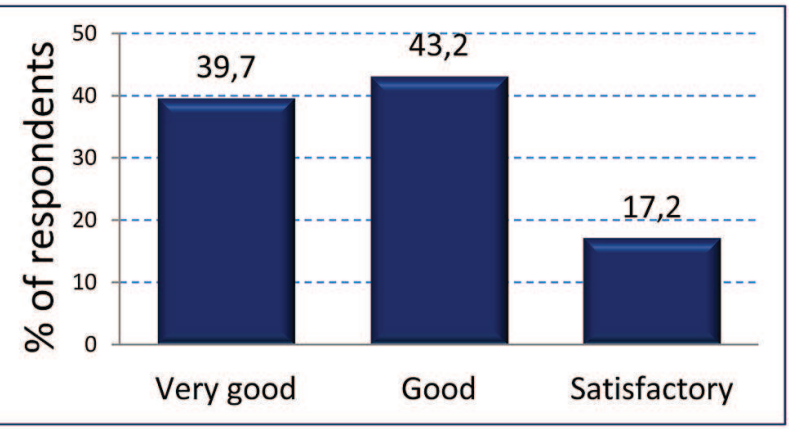

Fig. 3. Assessment of the usefulness of lectures and seminars for final exam preparation

The preliminary results of the survey stimulated the academic staff teaching biochemistry at the Medical University - Varna to devise and produce a teaching tool that could allow the students better understanding of the relationships between the different metabolic processes and their integrate regulation. The attention was focused on writing a seminar textbook in biochemistry which includes a complex of teaching aids and is closely related to pharmacy. Each topic consists of two parts, theoretical and laboratory exercises. The theoretical part contains logical exercises in biochemistry, and in addition, an introduction to pathobiochemistry, tests, illustrations, crosswords, "fill-in the gaps"-exercises oriented to specific seminar topics. The text was designed using

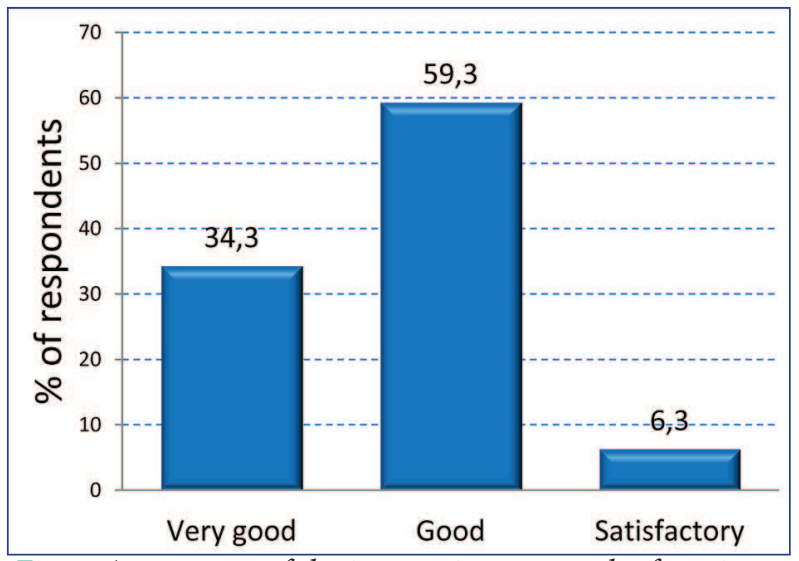

Fig. 4. Assessment of the innovative approach of seminars organization
The new seminar textbook received very good evaluation by $34.4 \%$ of the students, good - by $59.3 \%$, and only $6.3 \%$ gave a satisfactory score (Fig.4).

Beginning from the current 2014/2015 academic year all lecture notes were uploaded online using the new MUV e-learning platform Blackboard. Continuous assessment approach was adopted in addition to the final exam, as required by most of the students involved in the survey.

These student-centered activities aiming to improve pharmacy students' comprehension and interest to the discipline biochemistry were evaluated as positive by $71 \%$ of the students (Fig. 5).

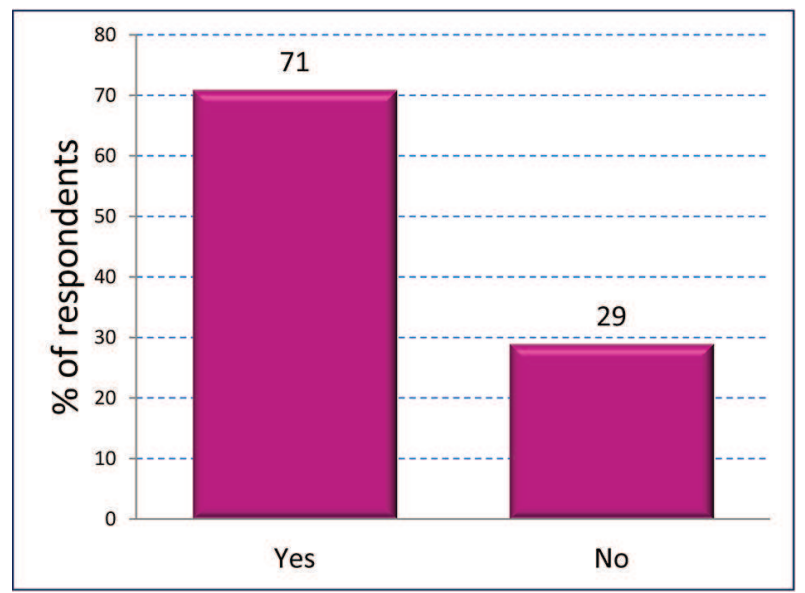

Fig. 5. Positive change in the interest of the respondents to the biochemistry training course 
Milena Pasheva, Milka Nashar, Yoana Kiselova-Kaneva et al.

\section{DISCUSSION}

Biochemistry is a compulsory basic discipline for pharmacy students, found by most of them as one of the highly difficult subjects. Although more than $50 \%$ of the interviewed estimate the lecture material as challenging, the majority ascertain that the content is relevant (92\%) and the lecturer's explanations are clear and apprehensible (70\%).

With respect to the structure of the Laboratory classes and the role of the assistant professor, which is necessary for the students' grasp of the material, almost half of the interviewed reflect that the amount of the lecture material, necessary for acquiring theoretical understanding of the subject, corresponds to the students' knowledge and consider the number of the laboratory exercises sufficient. The majority of students share the opinion that the assistant professor's explanations during the Laboratory classes are clear and concrete. In addition, the students acknowledge the genuinely expressed assistant professor 's interest towards their academic and professional success.

There are many alternative ways to teach, including in-class reviews, construction of concept maps (Gonzalez et al 2008, Morton et al 2008), or use of image-based manipulatives (Krontiris-Litowitz 2008). The use of multiple tools for teaching (Se et al 2008) appears to improve learning.

The innovative teaching method integrates a revision of theoretical knowledge through discussions on logical reasoning and practical exercises, as well as exercises specifically directed towards pharmaceutical practice, assembled in a handbook of practical exercises (drills, tasks). Most of the surveyed students evaluate this approach as very good or excellent. In addition to the positive evaluation of the content and teaching scheme in the subject of Biochemistry, performed by the Pharmacy students, an increased interest towards the subject has been observed in the course of instruction.

Our goal was to develop life-long learning habits in students and to help them learn biochemical concepts by understanding instead of memorizing. When active learning opportunities are offered, students become engaged, and this results in an improvement in their learning experience. In conclusion, the teaching of biochemistry was opti- mized and adjusted to the specific requirements of the pharmacy students, thus contributing to a better education quality of the future professionals.

\section{REFERENCES}

1. Lodish HF, Rodriguez RK, Klionsky DJ. Points of view: lectures: can't learn with them, can't learn without them. Cell Biol Educ. 2004;3:202-211.

2. Michael J. Where's the evidence that active learning works? Adv Physiol Educ. 2006;30:159-167.

3. Morton JP, Doran DA, Maclaren DP. Common student misconceptions in exercise physiology and biochemistry. Adv Physiol Educ. 2008;32:142-146.

4. Gonzalez HL, Palencia AP, Umana LA, Galindo L, Villafrade ML. Mediated learning experience and concept maps: a pedagogical tool for achieving meaningful learning in medical physiology students. Adv Physiol Educ. 2008;32:312-316.

5. Krontiris-Litowitz J. Using truncated lectures, conceptual exercises, and manipulatives to improve learning in the neuroanatomy classroom. Adv Physiol Educ. 2008;32:152-156.

6. Se A, Passos R, Ono A, and Lima M. The use of multiple tools for teaching medical biochemistry. Adv Physiol Educ. 2008;32:38-46. 